\title{
Detection of Antibody in Rainbow Trout against Aeromonas salmonicida by Enzyme-linked Immunosorbent Assay
}

\author{
Hiroshi Kodama, Akihiko Honda, Mohamed Moustafa, \\ Takeshi MIKamI, and Hisao Izawa \\ Department of Epizootiology, Faculty of Veterinary Medicine, \\ Hokkaido University, Sapporo 060, Japan
}

\begin{abstract}
An enzyme-linked immunosorbent assay (ELISA) was developed to detect anti-Aeromonas salmonicida antibody in rainbow trout immunized with the formalin-killed bacteria. Absorbance of the sera in ELISA correlated well with the serum dilutions and the agglutinin titer of each serum. The ELISA titers of the sera were much higher (usually 5 to 40 times) than the titers determined by agglutination test. By ELISA, antibody was detected in 1 out of 4 fish 2 weeks after immunization and in all of the fish 4 weeks after immunization. On the other hand, agglutinin was first detected 4 weeks after immunization. Inoculation of casein into fish before immunization showed immunostimulating effect on antibody production. The ELISA did not detect antibodies against A. hydrophila, A. punctata, A. liquefaciens, Vibrio anguillarum and other species of Vibrio in rainbow trout, whereas extensive cross reactions were observed among these bacteria and $A$. salmonicida by agglutination test and immunodiffusion.
\end{abstract}

\section{Introduction}

Aeromonas salmonicida infection in salmonid fish is called 'furunculosis' because of the formation of 'furuncle'-like lesions in the skin and muscles. Agglutination test has been used to detect fish antibody against $A$. salmonicida (CISAR and FRYER, 1974; Krantz and Heist, 1970; Krantz et al., 1963; MAISSE and DORSON, 1976; Weber and ZWICKER, 1979) or identify the bacteria (MCCARTHY and RaWle, 1975). However, cross reactions are frequently noticed among several species of Aeromonas and Vibrio in agglutination test and immunodiffusion (ID) (BULLOCK, 1966; JoHnson, 1977; LiU, 1961). To compensate for the shortcoming, we developed an enzyme-linked immunosorbent assay (ELISA) to detect anti- $A$. salmonicida antibody in rainbow trout immunized with the formalin-killed bacteria.

\section{Materials and Methods}

\section{Bacteria}

The bacteria used in this study are shown in Table 1. Strain of Aeromonas and Vibrio were kindly provided by Dr. D. K. Sakai (Hokkaido Fish Hatchery, Sapporo, Japan) and Mr. I. Komatsu
(Central Laboratories, Kyoritsu Shoji Co., Ibaraki, Japan), respectively. The strains of Aeromonas were grown at $20^{\circ} \mathrm{C}$ in heart infusion broth (Nissui, Tokyo, Japan). Vibrio were cultivated in the same medium containing $\mathrm{NaCl}$ at a final concentration of $1.5 \%$.

\section{ELISA}

The procedure of the ELISA for the detection of rainbow trout antibody against $A$. salmonicida is shown in Fig. 1. A. salmonicida strain NCMB1102 was used to prepare the antigen for the ELISA. Cell

Table 1. Bacterial strains used in the experiment

\begin{tabular}{ll}
\hline \multicolumn{1}{c}{ Species } & \multicolumn{1}{c}{ Strain } \\
\hline Aeromonas salmonicida & NCMB1102 \\
A. salmonicida & Y8309-5 \\
A. hydrophila & NCMB86 \\
A. hydrophila & IAM1018 \\
A. punctata & IAM1646 \\
A. punctata & TUF No. 1 \\
A. liquefaciens & ATCC11715 \\
A. lqiuefaciens & EFDL \\
Vibrio anguillarum & NCMB6 \\
V. anguillarum & NCMB571 \\
Vibrio sp. & N7802 \\
\hline
\end{tabular}



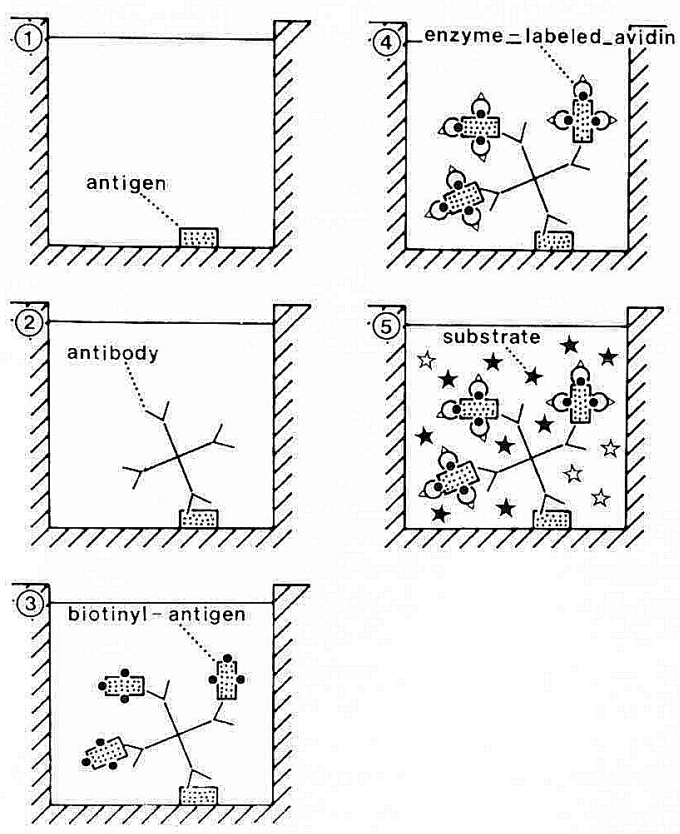

Fig. 1. Double antigen sandwich method for ELISA using biotinylated antigen and peroxidaseconjugated avidin for the detection of fish antibody.

lysate of the becteria was prepared by ultrasonification of $10 \%$ bacterial cell suspension $(\mathrm{w} / \mathrm{v})(2 \mathrm{~A}$ for 20 seconds) (Insonator Model 200M, Kubota, Tokyo, Japan). After centrifugation at 2,200 $\times \mathrm{g}$ for 15 minutes, the supernate was collected and used as antigen. Biotinylation of antigen was performed according to the method of GUESDON et al. (1979). Biotinyl-N-hydroxy succinimide ester (biotin) (E-Y Lab., San Mateo, Calif.) $(60 \mu \mathrm{g} / 0.06 \mathrm{~m} /)$ dissolved in dimethyl sulfoxide was mixed with $1 \mathrm{~m} /$ of the antigen ( $1 \mathrm{mg}$ of protein as determined by the method of Lowry et al. (1951)) equilibrated with $0.1 \mathrm{M} \mathrm{NaHCO}$. After incubation at $37^{\circ} \mathrm{C}$ for 4 hours, free biotin was removed by dialysis against. $0.05 \mathrm{M}$ phosphate buffer containing $0.5 \mathrm{M} \mathrm{NaCl}(\mathrm{pH}$ 8.0). Biotinylated antigen was stored at $-80^{\circ} \mathrm{C}$ until use. ELISA was performed as follows. Wells of a polystyrene microtiter plates (Linbro, Hamden, Connecticut) were coated with $0.2 \mathrm{~m} /$ of unbiotinylated $A$. salmonicida antigen $(1 \mu \mathrm{g})$ in phosphate buffer. The coated plates were incubated at $37^{\circ} \mathrm{C}$ for 120 minutes then washed 3 times with phosphate buffer containing $0.1 \%$ Tween 20 . One $\%$ bovine serum albumin $(0.2 \mathrm{~m} l)$ was added to each well, incubated at $37^{\circ} \mathrm{C}$ for 60 minutes, and then washed 3 times with the phosphate buffer-Tween solution. Serially diluted rainbow trout serum $(0.2 \mathrm{~m} /)$ in phosphate buffer was then added to the wells, and after incubation for 60 minutes at $20^{\circ} \mathrm{C}$, plates were washed and $0.2 \mathrm{~m} /$ of biotinylated $A$. salmonicida antigen $(2.5 \mu \mathrm{g})$ was added to each well. Plates were incubated at $20^{\circ} \mathrm{C}$ for 60 minutes, washed, then avidin conjugated with peroxidase (E-Y Lab.) $(0.25 \mu \mathrm{g} / 0.2 \mathrm{~m} /)$ diluted in phosphate buffer was added to each well. Plates were incubated at $37^{\circ} \mathrm{C}$ for 40 minutes, washed, then $0.2 \mathrm{~m} /$ of substrate solution $(0.2 \mathrm{~mm}$ azino-di-(3-ethylbenzthiazoline sulfonic acid) diluted in $0.05 \mathrm{M}$ citrate buffer $(\mathrm{pH}$ 4.0) containing $0.004 \% \mathrm{H}_{2} \mathrm{O}_{2}$ ) was added to each well. The plates were incubated for 60 minutes at $37^{\circ} \mathrm{C}$, then absorbance was measured by a spectrophotometer at a wavelength of $405 \mathrm{~nm}$ (Microelisa Automatic Reader, Flow Lab., Mclean, Virg.). The endpoint of ELISA was estimated from the dose-response curve and the titer was expressed as the reciprocal of the highest dilutions of serum showing an absorbance of over 0.20 .

\section{Rainbow Trout}

Rainbow trout (weighing 100 to $150 \mathrm{~g}$ ) were purchased from a commercial fish farm. Fish were acclimatized to laboratory conditions for 2 to 3 weeks in a 50 liter plastic aquarium filled with groud water (flow rate, 60 liters/hour, $13^{\circ} \mathrm{C}$ ) with aeration.

\section{Immunization of Rainbow Trout}

A. salmonicida strain NCMB1 102 cultivated for 48 hours were collected by centrifugation $(4,800 \times g$, 20 minutes) (KR/180FA, Kubota, Tokyo, Japan) and suspended in phosphate buffered saline (PBS, $\mathrm{pH} 7.2,0.15 \mathrm{M})$. After 2 washes with PBS, formaldehyde solution was added to the bacterial suspension at a final concentration of $0.3 \%$ and the suspension was continuously shaken overnight at $25^{\circ} \mathrm{C}$. Formaldehyde was removed by centrifugation and $10 \%$ suspension of the killed bacteria (w/v) was prepared with PBS. The bacterial suspension was emulsified in an equal volume of Freund's complete adjuvant and used as inoculum. Rainbow trout in 2 groups were injected intraperitoneally with $0.5 \mathrm{~m} /$ of inoculum. One group was inoculated intraperitoneally with $0.5 \mathrm{ml}$ of $8 \%$ casein (Wako Pure Chemical, Tokyo, Japan) 3 days before immunization. Sera $(1 \mathrm{~m} /)$ were collected periodically 
every week for 7 weeks, and fish were killed 10 weeks after immunization.

Antisera to other strains of Aeromonas and Vibrio were prepared in fish as described above except that sera were collected at appropriate time between 3 to 10 weeks after immunization instead of periodical bleeding.

Immunization of Rabbits with Aeromonas and Vibrio Anti-Aeromonas and anti-Vibrio rabbit sera were prepared as follows. One $\mathrm{m} /$ of inoculum prepared as described above was injected subcutaneously in the back of rabbits weighing $2,000 \mathrm{~g}$. The rabbits were given $1 \mathrm{~m} /$ of booster injection subcutaneously after 2 and 4 weeks, then blood was collected 1 week after the last injection.

\section{Agglutination Test}

Agglutination test was done as follows. Antisera were diluted 2-fold in PBS (pH 7.2) in 96-well microplates (Falcon, Oxnard, Calif.). To $0.025 \mathrm{~m} /$ of each dilution, $0.025 \mathrm{~m} l$ of $0.5 \%(\mathrm{w} / \mathrm{v})$ suspension of formalin-killed bacteria was added and incubated for 60 minutes at $30^{\circ} \mathrm{C}$. The plates were then left overnight at $4^{\circ} \mathrm{C}$. Agglutinin titer was expressed as the reciprocal of the highest dilution of serum that caused agglutination of the bacteria.

\section{ID}

Cell lysate of Aeromonas and Vibrio was used as antigen of ID. Ouchterlony plates were prepared with $1 \%$ Noble agar (Difco, Detroit, Michigan) in PBS (pH 7.2). Rabbit antisera were placed in central wells, and homologous and heterologous bacterial antigens were placed in peripheral wells. The plates were left at room temperature for 2 days then observed for precipitin lines.

\section{Results}

Titration of Antibody to A. salmonicida in Rainbow Trout Sera

Figure 2 shows the titration curves of 5 representative rainbow trout sera collected from fish immunized with $A$. salmonicida. Absorbance of the sera in ELISA correlated well with the serum dilutions and the agglutinin titer of each serum. The rainbow trout serum having agglutinin titer of $\geqq 2,048$ had the ELISA titer of $\geqq 10,240$. Another serum (agglutinin titer of 256) had ELISA titer of

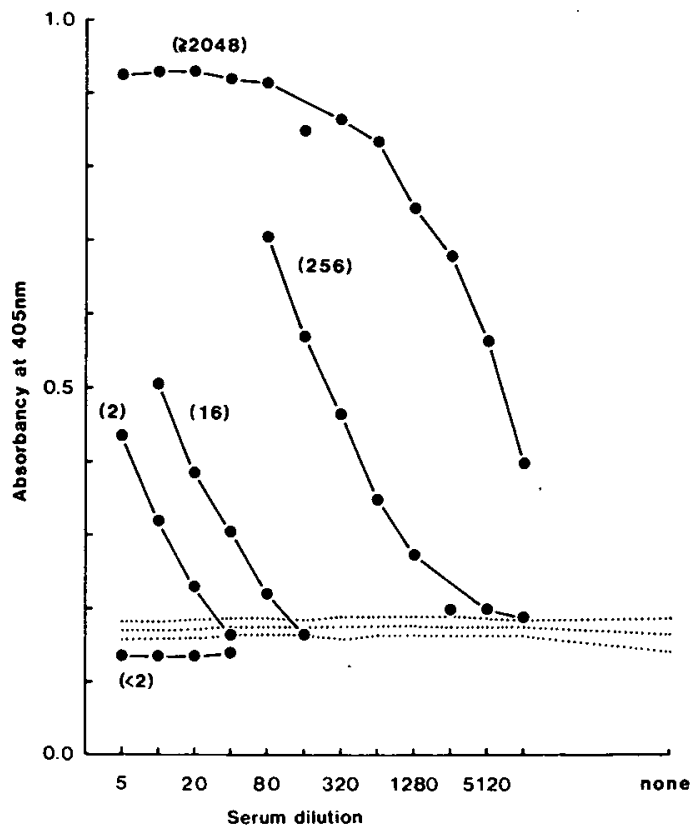

Fig. 2. Titration of rainbow trout sera. Mean value and $99 \%$ confidence limits of the value of a total of 36 normal rainbow trout sera from 5 separate experiments are shown as dotted lines. Agglutinin titer of each serum is indicated in parenthesis.

1,280. Thus, the ELISA was shown to have a higher sensitivity than agglutination test for detecting rainbow trout antibody against $A$. salmonicida.

\section{Cross Reactions among Strains of Aeromonas and Vibrio}

The occurrence of nonspecific cross reactions among 11 strains of Aeromonas and Vibrio were examined in agglutination test, ID and ELISA. Table 2 shows cross reactions in agglutination test using rainbow trout sera and formalin-killed bacteria. Extensive cross reactions were observed among these strains of Aeromonas and Vibrio. As shown in Table 3, cross reactions were also observed in ID when rabbit antisera were tested against cell lysates of each strain of Aeromonas and Vibrio.

To examine the occurrence of cross reactions in the ELISA, a total of 24 rainbow trout sera against $V$. anguillarum, Vibrio sp., A. hydrophila, A. punctata or $A$. liquefaciens was tested against antigen perpared from $A$. salmonicida NCMB1102 strain. Though the homologous agglutinin titers of the sera 
Table 2. Cross reactions between Aeromonas and Vibrio by agglutination test

\begin{tabular}{|c|c|c|c|c|c|c|c|c|c|c|c|}
\hline \multirow{2}{*}{ Antigen } & \multicolumn{11}{|c|}{ Antiserum (rainbow trout serum) } \\
\hline & (1) & $(2)$ & (3) & (4) & $(5)^{11}$ & (6) & (7) & $(8)$ & (9) & $(10)$ & (11) \\
\hline (1) Vibrio anguillarum NCMB6 & 16 & 4 & 64 & - & 4 & 4 & $.2)$ & 16 & . & 4 & 8 \\
\hline (2) $V$, anguillarum NCMB571 & 4 & 512 & 16 & - & 4 & 2 & . & 16 & . & 4 & 8 \\
\hline (3) Vibrio sp. N7802 & 4 & 32 & 256 & - & 4 & 2 & . & 16 & . & 8 & 8 \\
\hline (4) Aeromonas salmonicida NCMB1102 & 4 & 2 & 8 & 512 & 32 & 4 & . & 16 & . & 8 & 16 \\
\hline (6) A. hydrophila NCMB86 & 32 & - & - & 4 & - & 64 & . & - & . & - & 2 \\
\hline (7) A. hydrophila IAM 1018 & 2 & - & 16 & - & 2 & 4 & . & - & . & 8 & 16 \\
\hline (8) A. punctata TUF No. 1 & 4 & 4 & 16 & - & 16 & 4 & . & 64 & . & 8 & 16 \\
\hline (9) A. punctata IAM1646 & 8 & 128 & 16 & 16 & 16 & 8 & . & 16 & . & 128 & 16 \\
\hline (10) A. liquefaciens ATCC11715 & 8 & 32 & 64 & 4 & 16 & 64 & . & 8 & . & 32 & 8 \\
\hline (11) A. liquefaciens EFDL & 4 & 2 & 16 & 2 & 4 & 4 & . & 2 & $\cdot$ & 4 & 128 \\
\hline
\end{tabular}

1) Anti-A. salmonicida (Y8309-5 strain) rainbow trout serum.

2) Not tested.

Table 3. Cross Reactions between Aeromonas and Vibrio by immunodiffusion test

\begin{tabular}{|c|c|c|c|c|c|c|c|c|c|c|c|}
\hline \multirow{2}{*}{ Antigen } & \multicolumn{11}{|c|}{ Antiserum (rabbit serum) } \\
\hline & (1) & (2) & (3) & (4) & (5) & (6) & (7) & (8) & (9) & $(10)$ & (11) \\
\hline (1) Vibrio anguillarum NCMB6 & + & + & + & - & + & + & - & - & - & + & - \\
\hline (2) $V$. anguillarum NCMB571 & + & + & + & - & + & + & - & - & + & + & + \\
\hline (3) Vibrio sp. N7802 & + & + & + & - & + & + & - & - & + & + & + \\
\hline (4) Aeromonas salmonicida NCMB1102 & + & + & - & + & + & + & + & + & + & + & + \\
\hline (5) A: salmonicida Y8309-5 & + & + & + & + & + & + & + & + & + & + & + \\
\hline (6) A. hydrophila NCMB86 & + & + & + & - & + & + & + & + & + & + & + \\
\hline (7) A. hydrophila IAM 1018 & + & + & - & - & + & + & + & + & + & + & + \\
\hline (8) A. punctata TUF No. 1 & + & + & - & + & + & + & + & + & + & + & + \\
\hline (9) A. punctata IAM1646 & + & + & - & - & + & + & + & + & + & + & + \\
\hline (10) A. liquefaciens ATCC 11715 & - & - & - & - & + & + & + & + & + & + & + \\
\hline (11) A. liquefaciens FEDL & - & - & - & - & + & + & + & + & + & + & + \\
\hline
\end{tabular}

Table 4. Cross reactions between Aeromonas and Vibrio by ELISA

\begin{tabular}{lccl}
\hline \multicolumn{1}{c}{$\begin{array}{c}\text { Antiserum } \\
\text { (rainbow trout serum) }\end{array}$} & $\begin{array}{c}\text { No. sera } \\
\text { tested }\end{array}$ & $\begin{array}{c}\text { Agglutinin } \\
\text { titer }^{1)}\end{array}$ & ELISA titer $^{2)}$ \\
\hline Anti-Vibrio anguillarum NCMB6 & 4 & $32-1024$ & $<5,<5,<5,<5$ \\
Anti-V. anguillarum NCMB571 & 4 & $8-16$ & $<5,<5,<5,<5$ \\
Anti-Vibrio sp. N7802 & 3 & $128-256$ & $5,<5,<5$, \\
Anti-Aeromonas hydrophila NCMB86 & 4 & $2-512$ & $<5,<5,<5,<5$, \\
Anti-A. punctata TUF No. I & 2 & 128,256 & $<5,<5$, \\
Anti- $A$. liquefaciens ATCC11715 & 4 & $16-128$ & $5,<5,<5,<5$, \\
Anti- $A$. liquefaciens $E F D L$ & 3 & 256 & $<5,<5,<5$, \\
\hline
\end{tabular}

i) Against homologous bacterial cell suspensions killed by formalin.

2) Against $A$. salmonicida (NCMB1102 strain) antigen. 

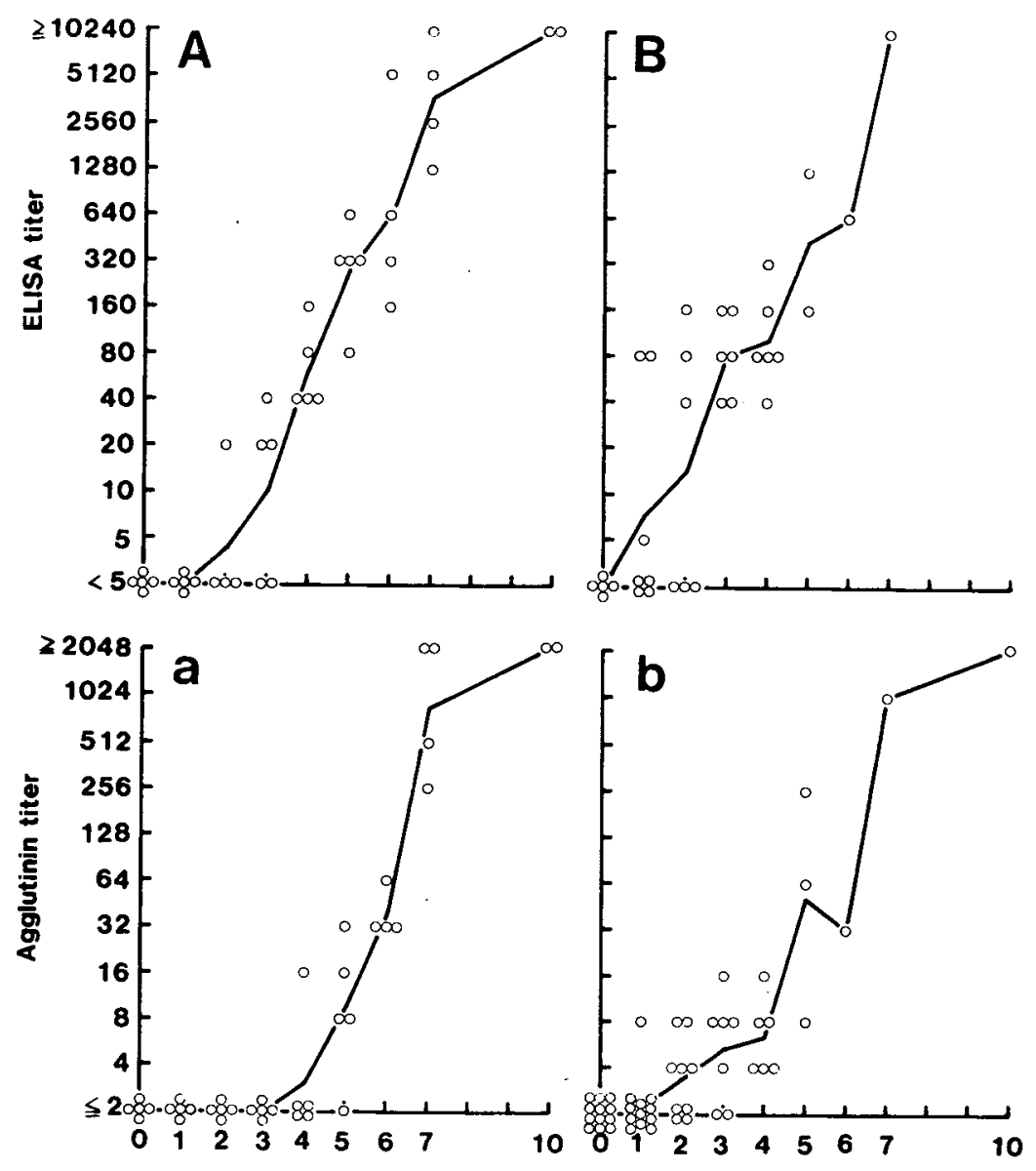

Weeks after immunization

Fig. 3. Titration of rainbow trout antibodies against Aeromonas salmonicida and the effect of pretreatment of rainbow trout with casein on antibody production. (A) ELISA titer and (a) agglutinin titer of sera from immunized fish. (B) ELISA titer and (b) agglutinin titer of casein treated-immunized fish.

differed from each other, the majority of the sera gave the titer of $<5$ when titrated against $A$. salmonicida by the ELISA (Table 4). These results indicated that there was minimal cross reactions in the ELISA.

\section{Occurence of Antibodies in Rainbow Trout Immu- nized with $A$. salmonicida}

Development of antibodies in rainbow trout immunized with formalin-killed bacteria and the effect of pre-inoculation of casein on antibody production were examined. Antibody titers of the sera were determined by the ELISA and agglutination test. In casein untreated group, agglutinin was first detected in 1 out of 5 fish 4 weeks after immunization and the titers increased thereafter (Fig. 3a). When these sera were titrated by the ELISA, however, antibody was first detected in 1 of 4 fish 2 weeks after immunization and all of the sera were positive 4 weeks after immunization (Fig. 3A). Figs. 3B and 3b show the increase of antibody titers in rainbow trout inoculated with casein then immunized with bacteria. In both ELISA (Fig. 3B) and agglutination test (Fig. 3b), antibody was first detected in some sera collected 1 week after immunization. Thus, when antibody production of casein-treated fish was compared with that of untreated fish, antibody was detected in the former group earlier than in the latter group. No antibody against $A$. salmonicida was detected by both ELISA and agglutination test 
in unimmunized control rainbow trout throughout the experimental period.

\section{Discussion}

Because of the high sensitivity and specificity, and the simplicity of the technique, the sandwich method of ELISA established in the present study was shown to be a very practical method to detect rainbow trout antibody against $A$. salmonicida. A remarkable feature of the established method is that the second antigen is covalently linked to biotin and therefore the preparation of anti-rainbow trout Ig rabbit serum is not required. Rainbow trout $\mathrm{Ig}$ binds to the first antigen via the Fab portions of antibody. Since it has been demonstrated that the structure of salmonid Ig is tetrameric (CISAR and Fryer, 1974; Kobayashi et al., 1982), 1 to 3 Fab portions should still be free after binding of antibody to the antigen as shown in Fig. 1. The free Fab portions of the test antibody bind the second antigen that has been linked to biotin and thus specific antibody against $A$. salmonicida antigen can be detected by this method.

The presence of common antigens among several species of Aeromonas and Vibrio is well-known (Bullock, 1966; Johnson, 1977; LiU, 1961). Extensive cross reactions were observed among strains of Aeromonas and Vibrio in agglutination test and ID in the present studies, however, very little cross reactions were observed when rainbow trout sera from fish immunized with either of these bacteria were titrated against $A$. salmonicida antigen in the ELISA. A. hydrophila and $A$. punctata are found frequently in intestinal bacterial flora of fish, and these bacteria also exist in water and soil (EGuSA, 1978). It is probable that fish produce antibodies against these bacteria when they are infected. Therefore, the ELISA developed in the present study can be used to detect anti- $A$. salmonicida antibody even if fish are dually infected under natural conditions with $A$. salmonicida and $A$. hydrophila or A. punctata.

The sensitivity of the ELISA was several times higher than that of agglutination test. Earlier experiments revealed that fish naturally infected with A. salmonicida developed only very low titers of agglutinating antibody (KRANTZ and HEIST, 1970; WEBER and ZWICKER, 1979). Therefore, it is expected that antibody can be detected effectively by the
ELISA not only in immunized but also in those that are naturally infected with $A$. salmonicida, and that the ELISA will be useful to detect the antibody in an early stage of the infection.

\section{Acknowledgements}

The authors wish to express our appreciation to Miss T. Ohmi for preparation of the manuscript. This work was supported by Grant-in-Aid for Cooperative Research from the Ministry of Education, Science and Culture of Japan.

\section{References}

Bullock, G. L. (1966): Precipitin and agglutinin reactions of aeromonads isolated from fish and other sources. Bull. Off. Int. Epiz., 65, 805-824.

CISAR, J. O. and J. L. FrYer (1974): Characterization of anti-Aeromonas salmonicida antibodies from coho salmon. Infect. Immun., 9, 236-243.

EgusA, S. (1978): Infectious Diseases of Fish. Kosei-sya Kosei-kaku, Tokyo.

Guesdon, J. L., T. Ternynck, and S. Avrameas (1979): The use of avidin-biotin interaction in immunoenzymatic techniques. J. Histochem. Cytochem., 27, 11311139.

JOHNSEN, G. S. (1977): Immunological studies on Vibrio anguillarum. Aquaculture, 10, 221-230.

Kobayashi, K., A. Hara, K. Takano, and H. Hiral (1982): Studies on subunit components of immunoglobulin $\mathrm{M}$ from a bony fish, the chum salmon (Oncorhynchus keta). Molecular Immunol., 19, 95-103.

Krantz, G. E. and C. E. Heist (1970): Prevalence of naturally acquired agglutinating antibodies against Aeromonas salmonicida in hatchery trout in central Pennsylvania. J. Fish. Res. Board Can., 27, 969-973.

Krantz, G. E., J. M. Reddecliff, and C. E. Heist (1963): Development of antibodies against Aeromonas salmonicida in trout. J. Immunol., 91, 757-760.

LiU, P. V. (1961): Observation on the specificities of extracellular antigens of the Genera Aeromonas and Serratia. J. Gen. Microbiol., 24, 145-153.

Lowry, O. H., N. J. Rosebrough, A. L. FARR, and R. J. Randall (1951): Protein measurement with the Folin phenol reagent. J. Biol. Chem., 193, 265-275.

MaIsse, G. and M. DoRson (1976): Production d'agglutinines anti Aeromonas salmonicida par la truite arc-en-ciel. Ann. Rech. Vétér., 7, 307-313.

MCCarthy, D. H. and C. T. RAWLE (1975): The rapid serological diagnosis of fish furunculosis caused by 'smooth' and 'rough' strains of Aeromonas salmonicida. J. Gen. Microbiol., 86, 185-187.

WebER, J. M. and B. M. ZWICKER (1979): Aeromonas salmonicida in Atlantic salmon (Salmo salar): occurrence of specific agglutinins to three bacterial pathogens. J. Fish. Res. Board Can., 36, 1102-1107. 